\title{
Rapid Simultaneous Determination of Olmesartan -Amlodipine and Hydrochlorothiazide in Combined Pharmaceutical Dosage Form by Stability-Indicating Ultra Performance Liquid Chromatography
}

\author{
Kakumani Kishore Kumar*, Chimalakonda Kameswara Rao, G. Madhusudan, Khagga Mukkanti \\ Centre for Chemical Science and Technology, Institute of Science and Technology, Jawaharlal Nehru \\ Technological University, Hyderabad, India \\ Email: *kkishorejntu@gmail.com
}

Received September 6, 2011; revised October 25, 2011; accepted November 5, 2011

\begin{abstract}
A simple, precise and rapid stability-indicating ultra-performance liquid chromatography (UPLC) method was developed for the simultaneous quantitative determination of Olmesartan, Amlodipine and Hydrochlorothiazide from their innovative Pharmaceutical combination drug product, with the presence of degradation products. It involved a $50 \mathrm{~mm} \times$ $2.1 \mathrm{~mm}, 1.8 \mu \mathrm{m}$ Phenyl column. The separation was achieved on simple gradient method. The mobile phase A contains a mixture of sodium perchlorate buffer $\mathrm{pH} 3.2(0.053 \mathrm{M})$ : acetonitrile in the ratio 90:10, v/v, and mobile phase B contains a mixture of sodium perchlorate buffer $\mathrm{pH} 3.2(0.053 \mathrm{M})$ : acetonitrile in the ratio 10:90, $\mathrm{v} / \mathrm{v}$. The flow rate was 0.7 $\mathrm{mL} \cdot \mathrm{min}^{-1}$ and column temperature was maintained at $55^{\circ} \mathrm{C}$. The gradient program $(\mathrm{T} / \% \mathrm{~B})$ was set as $0 / 10,2 / 50,4 / 80$, and 6.0/10. The detector wavelength was $271 \mathrm{~nm}$ for Hydrochlorothiazide, 215 for Olmesartan and $237 \mathrm{~nm}$ for Amlodipine. The retention times of Olmesartan, Amlodipine, and Hydrochlorothiazide are 3.5, 3.3 and 0.9 minutes; respectively. The total runtime was 6.0 minutes within which three active compounds and their degradation products were separated. The described method was validated with respect to system suitability, specificity, linearity, precision and accuracy. The precision of the assay method was evaluated by carrying out six independent assays of Olmesartan, Amlodipine, and Hydrochlorothiazide $\left(0.004 \mathrm{mg} \cdot \mathrm{mL}^{-1}, 0.001 \mathrm{mg} \cdot \mathrm{mL}^{-1}, 0.0025 \mathrm{mg} \cdot \mathrm{mL}^{-1)}\right.$. The accuracy of the method was evaluated in triplicate at three concentration levels, i.e. $50 \%, 100 \%$, and $150 \%$ of target test concentration. The described method was linear over the range, 2 to $6 \mu \mathrm{g} \cdot \mathrm{mL}^{-1}$ for Olmesartan, 0.5 to $1.5 \mu \mathrm{g} \cdot \mathrm{mL}^{-1}$ Amlodipine and 1.25 to $3.75 \mu \mathrm{g} \cdot \mathrm{mL}^{-1}$ for Hydrochlorothiazide. The method is fast and is suitable for high-throughput analysis of the drug and one can analyze about 240 samples per working day, facilitating the processing of large-number batch samples.
\end{abstract}

Keywords: Validation; Olmesartan; Amlodipine; Hydrochlorothiazide and UPLC

\section{Introduction}

Cardiovascular diseases (CVDs) are the disorders of heart and blood vessels and primarily include coronary heart disease, hypertension, cerebrovascular disease, peripheral artery disease, rheumatic heart disease, congenital heart disease and heart failure. CVDs are the major cause of death in developed countries and also are rapidly emerging as a main cause of death in the developing world. An estimated 17.5 million people died from CVDs till 2005, representing almost $30 \%$ of all the global deaths. It is projected that almost 20 million people will die from CVDs by 2015. The major risk factors involved in CVDs are high low density lipoprotein (LDL) cholesterol, raised blood pressure, increased serum homocysteine level and

*Corresponding author. platelet aggregation, which are primarily caused by unhealthy diet, physical inactivity and tobacco use. A novel formulation is developed using drugs Olmesartan, Amlodipine and Hydrochlorothiazide for CVDs.

Hydrochlorothiazide (HYD) is a thiazide diuretic (water pill). It decreases the amount of fluid in the body by increasing the amount of salt and water lost in the urine. Hydrochlorothiazide is used to lower blood pressure and to decrease edema (swelling), it is chemically described as 6-chloro-3,4-dihydro-2H-1,2,4-benzothiadiazine-7-sulfonamide 1,1-dioxide (Figure 1).

Amlodipine besylate (AMD) is in a class of drugs called beta-blockers. Beta-blockers affect the heart and circulatory system (arteries and veins). Amlodipine besylate is used to lower blood pressure, lower heart rate, reduce chest pain (angina), and to reduce the risk of re- 
<smiles>CCOC(=O)C1=C(COCCN)NC(C)=C(C(=O)OC)C1c1ccccc1Cl</smiles>

Amlodipine<smiles>NS(=O)(=O)c1cc2c(cc1Cl)NCNS2(=O)=O</smiles>

Hydrochlorothiazide

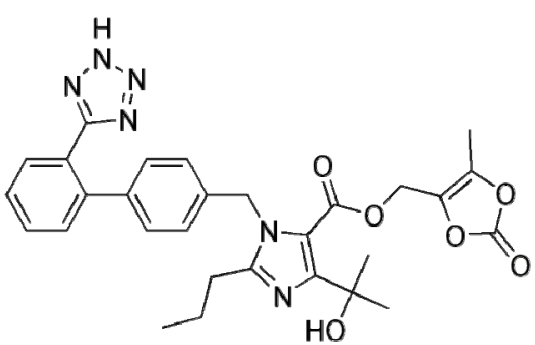

Olmesartan

Figure 1. Structures of Amlodipine, Hydrochlorothiazide and Olmesartan.

current heart attacks. It is chemically described as 4-[2hydroxy-3-[(1-methylethyl) amino] propoxy] benzeneacetamide (Figure 1).

Olmesartan (OLM) is an angiotensin II receptor (type $\mathrm{AT}_{1}$ ) antagonist used in the management of hypertension. Olmesartan prevents the constriction (narrowing) of blood vessels (veins and arteries). Olmesartan is a nonpeptide molecule, is chemically described as (5-methyl2-oxo-2H-1,3-dioxol-4-yl)methyl 4-(2-hydroxypropan-2yl)-2-propyl-1-(\{4-[2-(2H-1,2,3,4-tetrazol-5-yl)phenyl]p henyl $\}$ methyl)-1H-imidazole-5-carboxylate (Figure 1).

The ever-increasing need for speed and efficient use of time in the pharmaceutical and other fields, there is demand for the development of fast and high throughput analytical procedures. The rapid quantitative determination of combination drugs with big difference in label claims (20 mg for OLM and $12.5 \mathrm{mg}$ for AMD) with shorter run times is a challenge. For UPLC based assays, the processes of reducing analysis time while adequately resolving analytes from degradation products is often accomplished with column with small particles. The theoretical advantages for small particles are to get well resolved peaks with high theoretical plates over small concentration.

Present drug stability test guidance Q1A (R2) issued by international conference on harmonization (ICH) [1] suggest that stress studies should be carried out on a drug product to establish its inherent stability characteristics, leading to identification of degradation products and hence supporting the suitability of the proposed analytical procedures. It also requires that analytical test procedures for stability samples should be stability indicating and they should be fully validated.

Accordingly, the aim of the present study was to establish inherent stability of Olmesartan, Amlodipine besylate, and Hydrochlorothiazide through stress studies under a variety of ICH recommended test conditions [1-3] and to develop a rapid stability-indicating reverse phase assay method [4-6].

Literature survey reveals that a variety of spectrophotometric and chromatographic methods including UV, colorimetric determination, ratio derivative, and a stabi- lity- indicating HPLC methods have been reported for determination OLM, AMD and HYD either single or in combination with other drugs [7-12]. Where as no liquid chromatography method has been reported for simultaneous quantitative determination of OLM, AMD and HYD in the combined dosage form.

Hence a rapid simple reproducible Ultra performance liquid chromatography method was developed for simultaneous quantitative determination of OLM, AMD and HYD in pharmaceutical dosage forms in the presence of degradation products.

\section{Experimental}

\subsection{Chemicals and Reagents}

Standards Supplied by D.C.O office and tablets (40 mg of Olmesartan, $10 \mathrm{mg}$ of Amlodipine besylate, $25 \mathrm{mg}$ of Hydrochlorothiazide) were supplied by Diachii Sankyolaboratories limited, New Jersey. The HPLC grade acetonitrile, analytical grade sodium per chlorate and disodium hydrogen phosphate were purchased from Merck, Darmstadt, Germany. Water was prepared by using Millipore MilliQ Plus water purification system

\subsection{Instrumentation}

Acquity UPLC ${ }^{\mathrm{TM}}$ system (Waters, Milford, USA) used consisting of a binary solvent manager, a sample manager and a PDA detector. The out put signal was monitored and processed using Empower software, water bath equipped with MV controller (Julabo, Seelbach, Germany) was used for hydrolysis studies. Photo stability studies were carried out in a photo stability chamber (Sanyo, Leicestershire, UK). Thermal stability studies were performed in a dry air oven (MACK Pharmatech, Hyderabad, India).

\subsection{Chromatographic Conditions}

The chromatographic column used was Zorbax SB Phenyl, $50 \mathrm{~mm} \times 2.1 \mathrm{~mm}$ i.d with $1.8 \mu \mathrm{m}$ particles. The mobile phase A contains a mixture of sodium perchlorate buffer pH 3.2 (0.053 M): acetonitrile (90:10, v/v) and mobile 
phase B contains a mixture of sodium perchlorate buffer pH $3.2(0.053 \mathrm{M})$ : acetonitrile (10:90, v/v). The flow rate was $0.7 \mathrm{ml} \cdot \mathrm{min}^{-1}$ and column temperature was maintained at $55^{\circ} \mathrm{C}$. The detection wavelength was $271 \mathrm{~nm}$ for Hydrochlorothiazide, 215nm for Olmesartan and $237 \mathrm{~nm}$ for Amlodipine. The diluent contains a mixture of acetonitrile and methanol in the ratio 50:50 v/v.

\subsection{Preparation of Standard Solutions}

Stock standard solutions of OLM, AMD and HYD (0.40 $\pm 0.04 \mathrm{mg} \cdot \mathrm{mL}^{-1}$ of OLM, $0.1 \pm 0.01 \mathrm{mg} \cdot \mathrm{mL}^{-1}$ of AMD, $0.25 \pm 0.025 \mathrm{mg} \cdot \mathrm{mL}^{-1}$ of HYD) were prepared by dissolving appropriate amounts of the compounds in Diluent. Working solutions $0.004 \mathrm{mg} \cdot \mathrm{mL}^{-1}$ of OLM, 0.001 $\mathrm{mg} \cdot \mathrm{mL}^{-1}$ of AMD, $0.0025 \mathrm{mg} \cdot \mathrm{mL}^{-1}$ of HYD were prepared from above stock solution in diluent for assay determination.

The method does not. Involve any complicated sample preparation (Extraction of drugs from sample matrix), Internal standard is not used in the sample preparation. How ever the precision and accuracy results show that method is precise, linear and accurate without internal standard.

\subsection{Preparation of Sample Solution}

Weighed and crushed ten tablets into a clean and dry mortar-pestle. An equivalent to $40 \mathrm{mg}$ of Olmesartan, 10 $\mathrm{mg}$ of Amlodipine, $25 \mathrm{mg}$ of Hydrochlorothiazide was transferred to a $100 \mathrm{ml}$ volumetric flask, added $15 \mathrm{ml}$ of diluent and kept on rotary shaker for 20 minutes. Added $50 \mathrm{ml}$ of diluent and sonicated for 20 minutes. Made the volume to $100 \mathrm{ml}$ with diluent $\left(0.40 \mathrm{mg} \cdot \mathrm{mL}^{-1}\right.$ of OLM, $0.1 \mathrm{mg} \cdot \mathrm{mL}^{-1}$ of AMD, $0.25 \mathrm{mg} \cdot \mathrm{mL}^{-1}$ of HYD). About $0.1 \mathrm{ml}$ of supernant solution was taken and diluted to 100 $\mathrm{mL}$ with diluent to get working concentrators (0.004 $\mathrm{mg} \cdot \mathrm{mL}^{-1}$ of OLM, $0.001 \mathrm{mg} \cdot \mathrm{mL}^{-1}$ of AMD, 0.0025 $\mathrm{mg} \cdot \mathrm{mL}^{-1}$ of HYD). The solution was then filtered through $0.45 \mu$ (Nylon 66-membrane) filter.

\section{Results and Discussion}

\subsection{Chromatographic Conditions}

A Reverse phase UPLC method was proposed as a suitable method for quantitative determination of Amlodipine, hydrochlorothiazide and Olmesartan in Tribenzor Pharmaceutical tablets. The mobile phase conditions were optimized so that the three drugs would be separated in short run time.

After trying different columns, the final choice of the stationary phase that gave a satisfactory resolution and run time was the reverse phase column Agilent Zorbax SB Phenyl column $(50 \times 2.1 \mathrm{~mm}$ i.d, $1.8 \mu \mathrm{m}$ particle size). A series of aqueous mobile phases containing So- dium perchlorate buffer solution with different $\mathrm{pH}$ values and concentrations in combination with different volume fractions of acetonitrile as modifier were also tested. The best results were obtained by use of a mixture of $0.053 \mathrm{M}$ sodium perchlorate (adjusted to $\mathrm{pH} 3.2$ with Ortho Phosphoric acid) and Acetonitrile in the ratio (90:10)used as a mobile phase $\mathrm{A}$ and Acetonitrile and $0.053 \mathrm{M}$ sodium perchlorate(adjusted to $\mathrm{pH} 3.2)$ in the ratio $(90: 10$ $\mathrm{v} / \mathrm{v}$;)used as mobile phase B. All experiments were carried out at $55^{\circ} \mathrm{C}$.

To determine the appropriate wave length for simultaneous determination of Amlodipine, hydrochlorothiazide and Olmesartan, solutions of these compounds were injected into the UPLC system and obtained the UV spectra in the range $200-400 \mathrm{~nm}$ by DAD. The UV spectra of the solutions obtained showed the absorptions $215 \mathrm{~nm}$ for Olmesartan, $271 \mathrm{~nm}$ for Hydrochlorothiazide and 237 $\mathrm{nm}$ for Amlodipine for UV maximums. (Figure 2) Under the optimum chromatographic conditions, the retention times obtained for Hydrochlorothiazide, Amlodipine and Olmesartan were 0.9, 3.3 and 3.5 min, respectively (Figure 3). The retention times of individual analyte are confirmed by injecting individual working solutions (Figure 4). The result of resolution (Rs), tailing factor and theoretical plate number are reported in Table $\mathbf{1}$.

\subsection{Validation}

After establishing the optimal conditions for the separation, the specificity, linearity, precision, accuracy, limit of detection and limit of quantification were determined for the three drugs.

\subsection{Linearity}

The linearity was determined for three drugs, Hydrochlorothiazide, Amlodipine and Olmesartan, separately by plotting a calibration graph of peak area against their respective concentration. Made a calibration curve $(n=5)$ by using $50 \%, 75 \%, 100 \%, 125 \%, 150 \%$ standard solution of each drug with respect to test concentration of $0.004 \mathrm{mg} \cdot \mathrm{mL}^{-1}$ of OLM, $0.001 \mathrm{mg} \cdot \mathrm{mL}^{-1}$ of AMD, $0.0025 \mathrm{mg} \cdot \mathrm{mL}^{-1}$ of HYD were prepared from above stock solu- tion in diluent.We have taken concentration of analyte in $\mathrm{X}$-axis and analyte response (Peak area) on Y-axis .From the calibration curve, it was clear that Hydrochlorothi- azide, Amlodipine and Olmesartan had linearity between $1.25-3.75 \mu \mathrm{g} / \mathrm{ml}$ for Hydrochlorothiazide, 0.5 - $1.5 \mu \mathrm{g} / \mathrm{ml}$ for Amlodipine and 2 - $6 \mu \mathrm{g} / \mathrm{ml}$ for Olmesartan. The linear regression equation for three drugs was. The linearity data are reported in Table 2.

$$
\begin{gathered}
\text { Hydrochlorothiazide: } \mathrm{Y}=32284 \mathrm{x}-172\left(\mathrm{r}^{2}=0.997\right)(\mathrm{n}=5) \\
\text { Amlodipine: } \mathrm{Y}=14617 \mathrm{x}-128\left(\mathrm{r}^{2}=0.998\right)(\mathrm{n}=5) \\
\text { Olmesartan: } \mathrm{Y}=31693 \mathrm{x}+433.6\left(\mathrm{r}^{2}=0.997\right)(\mathrm{n}=5)
\end{gathered}
$$


Table 1. System suitability parameters.

\begin{tabular}{|c|c|c|c|}
\hline System suitability test parameters & HYD & AMD & OLM \\
\hline Retention time (min) (mean \pm S.D., $\mathrm{n}=6$ ) & $0.93 \pm 0.01$ & $3.32 \pm 0.0010$ & $3.529 \pm 0.01$ \\
\hline Repeatability of retention time; RSD\% (n = 6) & 0.3342 & 0.0300 & 0.0460 \\
\hline Repeatability of peak area; RSD\% $=($ S.D. $/$ mean $) \times 100$ & 0.0752 & 0.5403 & 0.1501 \\
\hline Resolution (Rs) & - & 16.9 & 2.3 \\
\hline Tailing factor (asymmetric factor) & 1.4 & 1.2 & 1.2 \\
\hline
\end{tabular}

Table 2. Linearity.

\begin{tabular}{ccccc}
\hline Analyte & Concentration range & $\mathrm{r}^{2}$ & Slope & Intercept \\
\hline Olmesartan & $2.0-6.0 \mu \mathrm{g} \cdot \mathrm{ml}^{-1}$ & 0.9973 & 31,693 & 433.6 \\
Amlodipine & $0.5-1.5 \mu \mathrm{g}_{\mathrm{ml}}^{-1}$ & 0.9980 & 14,617 & -128 \\
Hydrochlorothiazide & $1.25-3.75 \mu \mathrm{g} \cdot \mathrm{ml}^{-1}$ & 0.9972 & 32,284 & -1732 \\
\hline
\end{tabular}

${ }^{\mathrm{a} C o r r e l a t i o n ~ c o e f f i c i e n t . ~}$
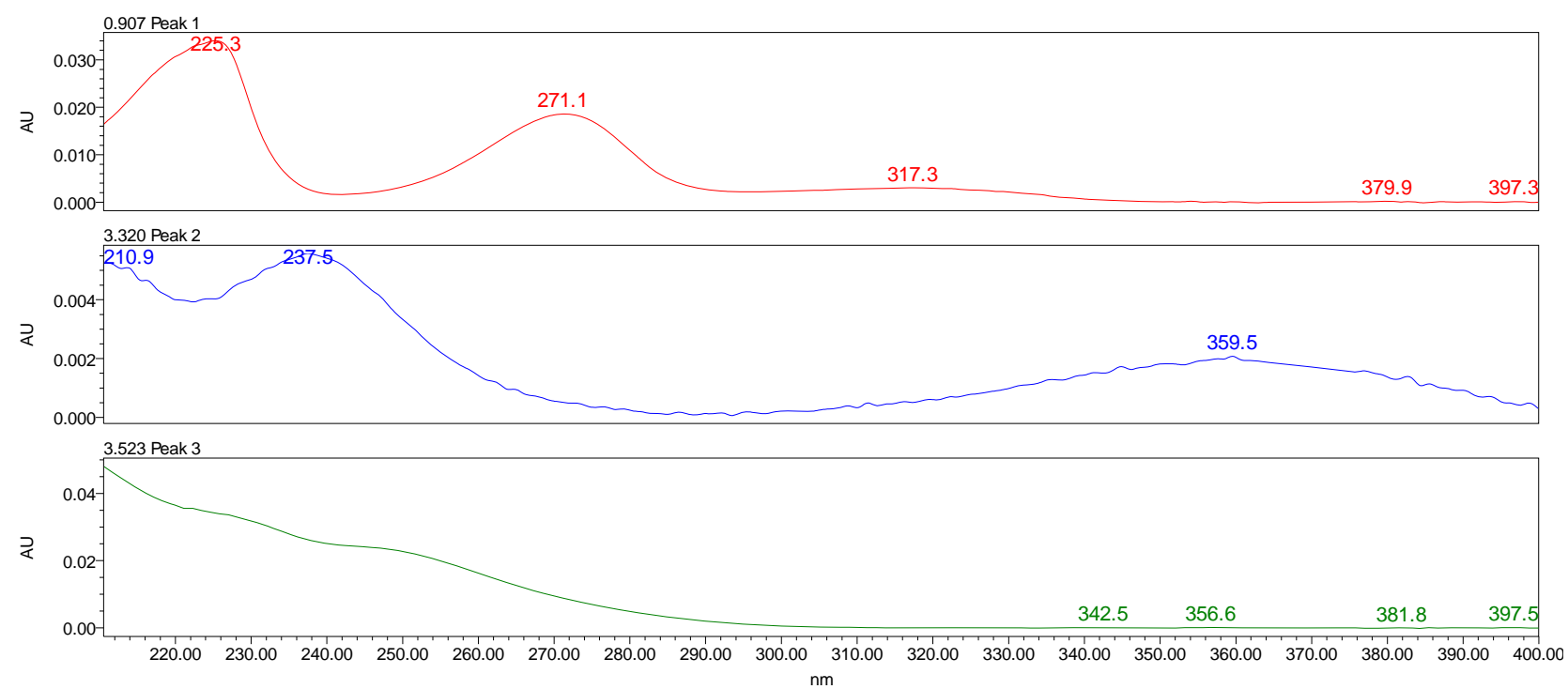

Figure 2. UV spectra of Hydrochlorothiazide, Amlodipine and Olmesartan.

PURITY CHROMATOGRAM

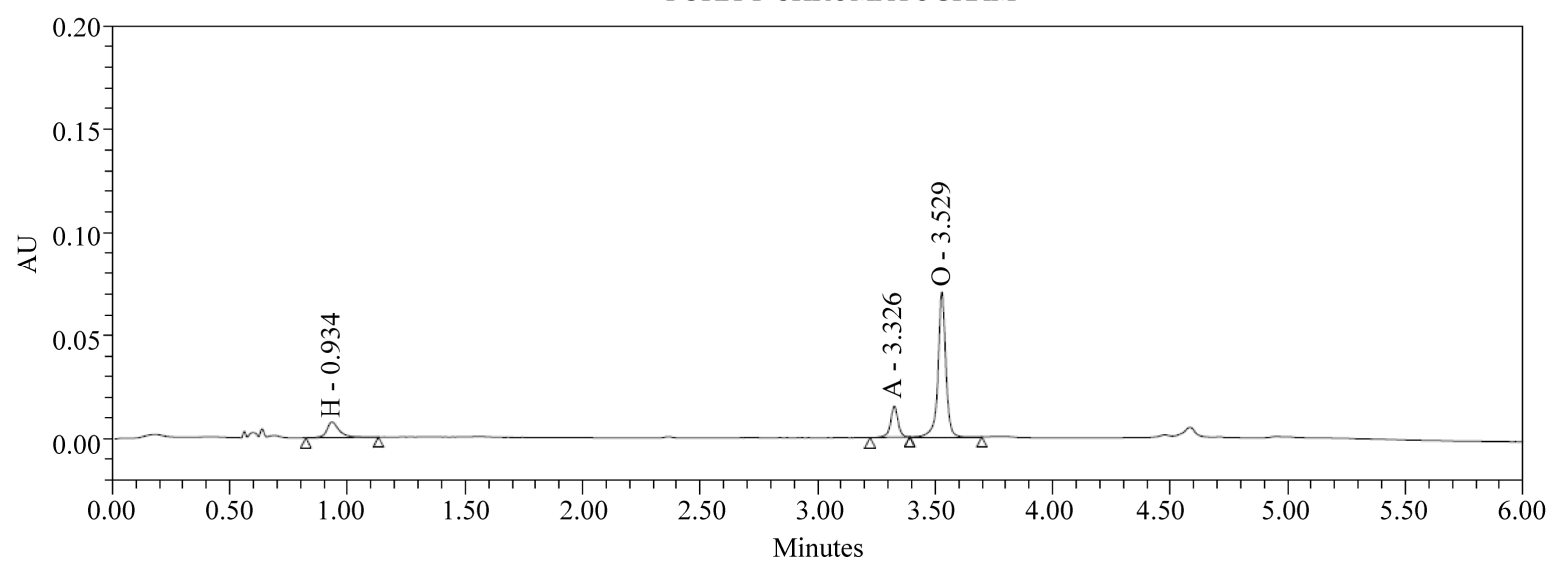

Figure 3. Chromatogram of Hydrochlorothiazide, Amlodipine and Olmesartan in Pharmaceutical sample solution and their retention times. 

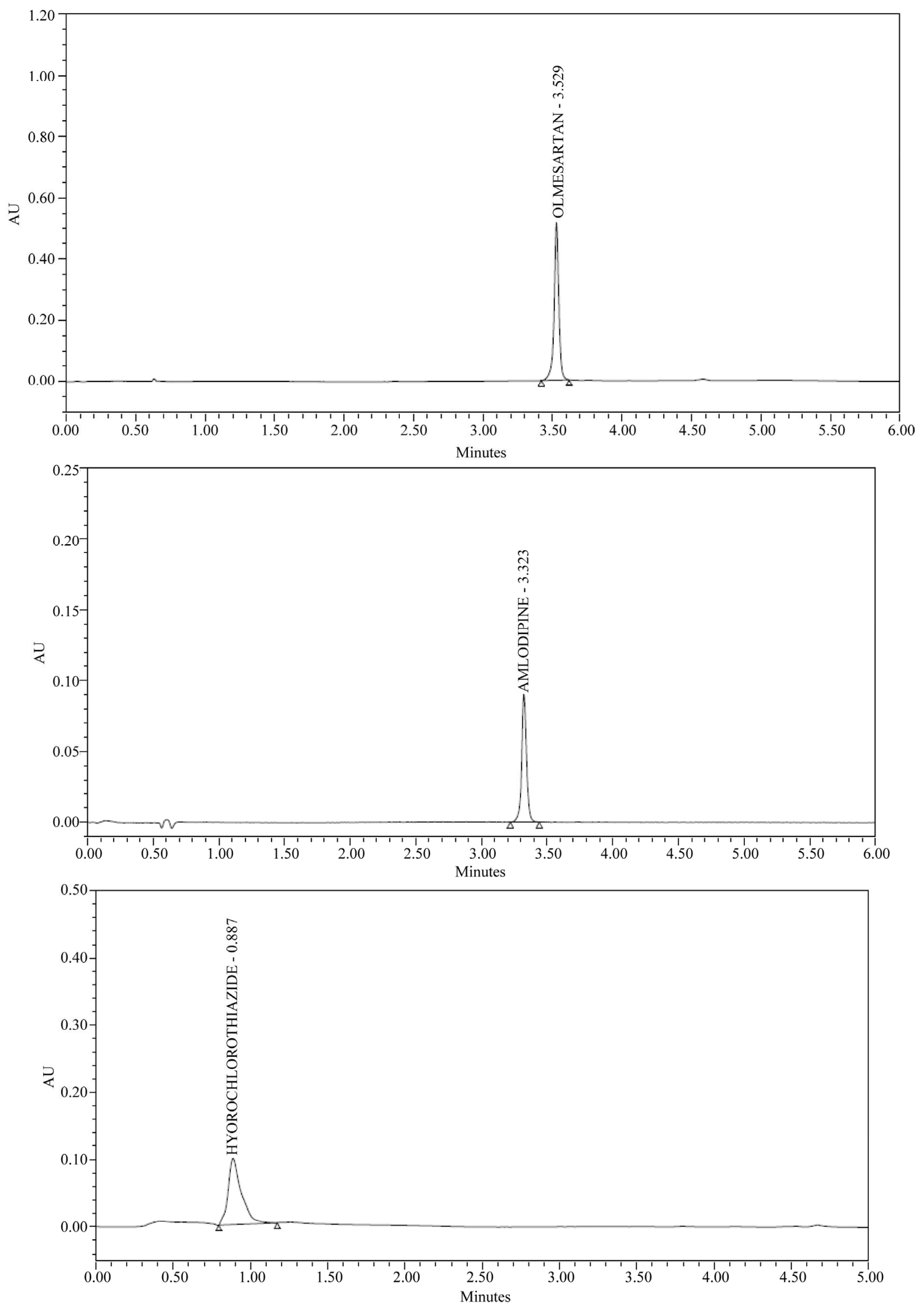

Figure 4. Chromatograms of individual samples and their retention times. 
where $\mathrm{y}$ is peak area and $\mathrm{x}$ is concentration

\subsection{Accuracy}

To check the accuracy of the developed method, analytical recovery study experiments were carried out by the standard addition method. From that total amount of the drug found, the percentage recovery was calculated. The recovery values for the three compounds are in the range of 99.5 - 101.50. The accuracy data are reported in Table 3.

\subsection{Precision and LOD and LOQ}

Precision was determined by studying the repeatability and intermediate precision. Repeatability results indicate the precision under the same operating conditions over a short interval time interassay precision. The standard deviation, coefficient of variance and standard error were calculated for three drugs. The results are mentioned in Table 4 Intermediated precision was carried out by doing intra and interday precision studies. In the intraday study, the concentrations of three drugs were calculated on the same day at interval of $1 \mathrm{~h}$. In the interday study, the concentrations of drug contents were calculated on three different days, and the study express within laboratory variation in different days. In both intra and interday precision studies for the methods, COV\% values were not more than $2 \%$, which indicates good intermediate precision (Table 4).

LOD and LOQ studies were carried out to evaluate the detection and quantization limits of the method to determine the presence of any impurities by using following equation:

$$
\mathrm{LOD}=3.3 \sigma / \mathrm{S}
$$

$$
\mathrm{LOQ}=10 \sigma / \mathrm{S}
$$

where $\sigma$ is the standard deviation and $\mathrm{S}$ is the slope of the curve.

The result is reported in Table 4. The developed method was precise for quantitative study because the precision study was found statistically significant (COV\% $<2$ and S.D. $<1.0$ for intra and interday studies).

\subsection{Selective and Specificity}

To check the selectivity of the developed method, solutions of the three drugs were injected into the system, and three sharp peaks for Hydrochlorothiazide, Amlodipine and Olmesartan were obtained at retention times 0.93, 3.3 and 3.5 min respectively in reference solution.

Specificity of the method was assessed by comparing the chromatograms obtained from standard drugs (Figure 3). The chromatogram obtained from tablet (Figure 5) solutions. Because the retention time of standard drugs and retention time of three drugs in sample solution were the same, the method was specific. The developed method was specific and selective as no interference of excipients was found.

\subsection{Forced Degradation Studies}

Stress testing of a drug substance can help to identify the likely degradation products, which can help to establish the degradation pathways and the intrinsic stability of the molecule.

All stress decomposition studies were performed at an initial drug concentration $4.0 \mu \mathrm{g} \cdot \mathrm{mL}^{-1}$ of OLM, 1.0 $\mu \mathrm{g} \cdot \mathrm{mL}^{-1}$ of AMD, $2.5 \mu \mathrm{g} \cdot \mathrm{mL}^{-1}$ of HYD. The degradation conditions are selected on the basis of literature survey [13-17].

\begin{tabular}{|c|c|c|c|c|c|c|}
\hline Analyte & Recovery level & Actual Conc. $\left(\mu \mathrm{g} \cdot \mathrm{mL}^{-1}\right)$ & Found Conc. $\left(\mu \mathrm{g} \cdot \mathrm{mL}^{-1}\right)$ & \%Recovery & \%RSD & $\%$ Error $^{\mathrm{a}}$ \\
\hline \multirow{3}{*}{ Olmesartan } & $50 \%$ & 2.1 & 2.04 & 101.49 & 0.66 & 3.0 \\
\hline & $100 \%$ & 4.04 & 4.02 & 99.50 & 0.45 & -2.0 \\
\hline & $150 \%$ & 6.03 & 6.05 & 100.33 & 0.44 & 2.0 \\
\hline \multirow{3}{*}{ Amlodipine } & $50 \%$ & 0.51 & 0.51 & 100.00 & 0.25 & 0.00 \\
\hline & $100 \%$ & 1.02 & 1.03 & 100.98 & 0.54 & 1.00 \\
\hline & $150 \%$ & 1.52 & 1.54 & 101.32 & 0.67 & 2.00 \\
\hline \multirow{3}{*}{ Hydrochlorothiazide } & $50 \%$ & 1.251 & 1.253 & 100.16 & 0.76 & 0.2 \\
\hline & $100 \%$ & 2.502 & 2.506 & 100.16 & 0.67 & 0.4 \\
\hline & $150 \%$ & 3.752 & 3.756 & 100.11 & 0.54 & 0.4 \\
\hline
\end{tabular}

Table 3. Accuracy results of OLM, AMD and HYD from tablets $(n=3)$.

[ [found conc.: actual conc./actual conc. $] \times 100$. 
Table 4. Intra-day and inter-day precision results of OLM, AMD and HYD from tablets (n = 6).

\begin{tabular}{ccccccccccc}
\hline \multirow{2}{*}{ Day } & Active & $\begin{array}{c}\text { Pre-1 } \\
\text { \% Assay }\end{array}$ & $\begin{array}{c}\text { Pre-2 } \\
\text { \% Assay }\end{array}$ & $\begin{array}{c}\text { Pre-3 } \\
\text { \% Assay }\end{array}$ & $\begin{array}{c}\text { Pre-4 } \\
\text { \% Assay }\end{array}$ & $\begin{array}{c}\text { Pre-5 } \\
\text { \% Assay }\end{array}$ & $\begin{array}{c}\text { Pre-6 } \\
\text { \% Assay }\end{array}$ & $\begin{array}{c}\text { Mean } \\
\text { RSD }\end{array}$ \\
\hline \multirow{2}{*}{ Intra-day } & OLM & 100.15 & 100.06 & 99.85 & 99.78 & 99.67 & 99.84 & 99.89 & 0.18 \\
precision & AMD & 100.02 & 100.17 & 99.56 & 99.73 & 99.84 & 99.95 & 99.88 & 0.22 \\
& HYD & 99.69 & 99.75 & 99.86 & 99.95 & 99.71 & 99.98 & 99.82 & 0.13 \\
\multirow{5}{*}{$\begin{array}{l}\text { Inter-day } \\
\text { precision }\end{array}$} & OLM & 100.02 & 100.14 & 100.08 & 99.87 & 99.91 & 99.94 & 99.99 & 0.10 \\
& AMD & 100.17 & 100.24 & 99.97 & 99.88 & 99.94 & 100.05 & 100.04 & 0.14 \\
& HYD & 99.78 & 99.67 & 99.94 & 99.86 & 99.67 & 99.81 & 99.79 & 0.11 \\
\hline
\end{tabular}

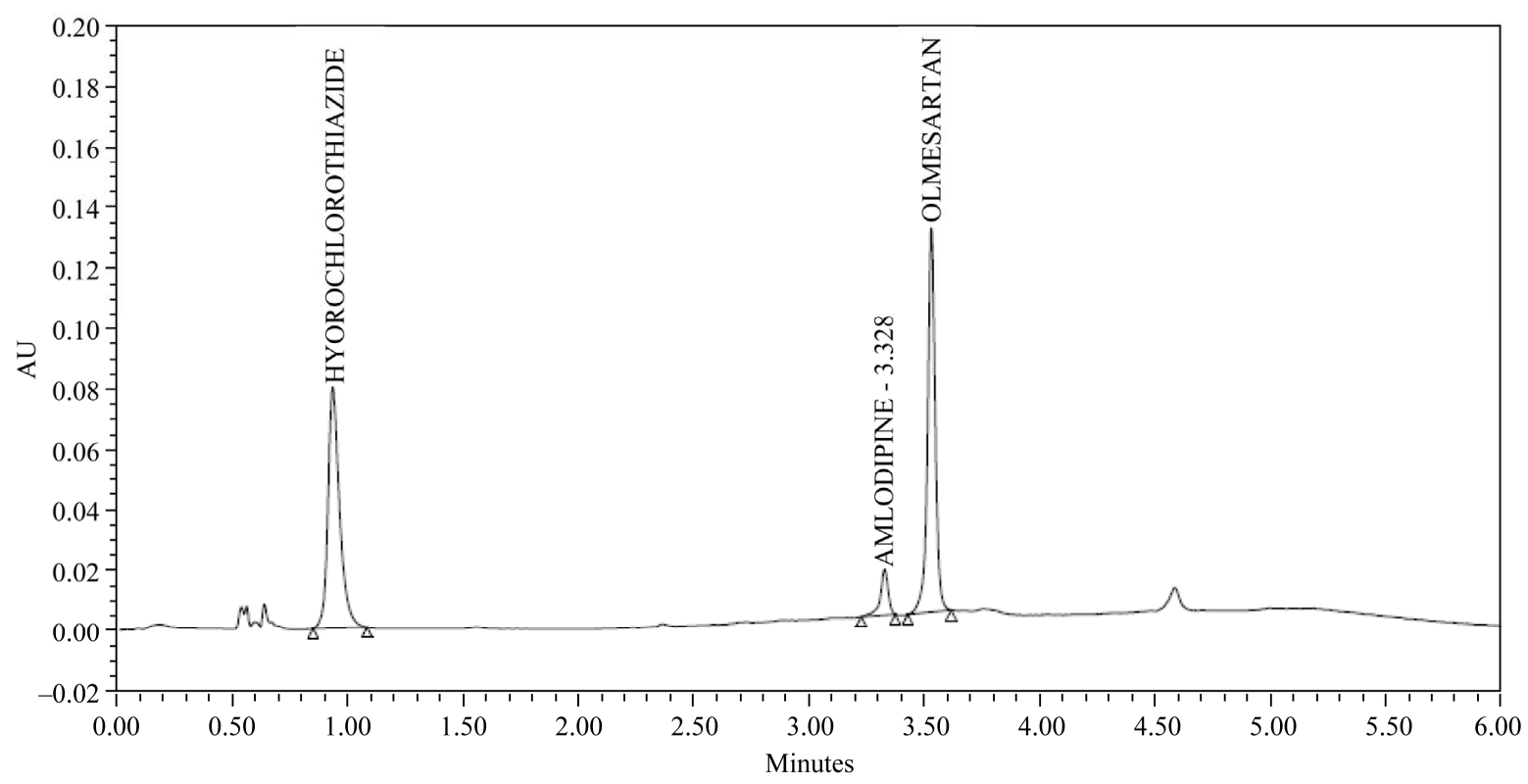

Figure 5. Chromatogram of Hydrochlorothiazide, Amlodipine and Olmesartan in sample solution and their retention times.

\subsection{Hydrogen Peroxide Induced Degradation}

For hydrogen peroxide-induced degradation, the studies were carried out at room temperature in $1 \%$ hydrogen peroxide for 6 hours. Shows the major degradation found at RT 2.3. All the major and minor degradation products were well separated from OLM, AMD and HYD peaks. The peak purity is checked for OLM, AMD and HYD and the results are summarized in Table 5.

\subsection{Acid Induced Degradation}

Acid hydrolysis was performed in $1 \mathrm{~N} \mathrm{HCl}$ at $60^{\circ} \mathrm{C}$ for 6 hours. Shows the major degradation found at Rt 1.2 and all the major and minor degradation products were well separated from OLM, AMD and HYD peaks. The peak purity is checked for OLM, AMD and HYD and the results are summarized in Table 5.

\subsection{Photo Degradation}

Photo degradation studies were carried out at according to option 2 of Q1B in ICH guidelines [3]. Samples were exposed to light for an overall illumination of 1.2 million lux hours and an integrated near ultraviolet energy of 200 watt $\mathrm{hm}^{2}$. Samples were withdrawn at appropriate time and subjected to UPLC analysis after suitable dilution $\left(0.004 \mathrm{mg} \cdot \mathrm{mL}^{-1}\right.$ of OLM, $0.001 \mathrm{mg} \cdot \mathrm{mL}^{-1}$ of AMD, $0.0025 \mathrm{mg} \cdot \mathrm{mL}^{-1}$ of HYD). The drugs OLM, AMD and HYD are stable under photolytic condition. The peak purity is checked for OLM, AMD and HYD and the results are summarized in Table 5.

\subsection{Accuracy}

The accuracy of an analytical method expresses the closeness between the reference value and found value. The accuracy of the method was evaluated in triplicate at three concentration levels, i.e. 50\%, 100\% and 150\% of target test concentration $\left(0.004 \mathrm{mg} \cdot \mathrm{mL}^{-1}\right.$ of OLM, 0.001 $\mathrm{mg} \cdot \mathrm{mL}^{-1}$ of AMD, and $0.0025 \mathrm{mg} \cdot \mathrm{mL}^{-1}$ of HYD) in tablets. The results obtained are shown in Table 3.

\subsection{Solution Stability and Mobile Phase Stability}

The solution stability of OLM, AMD and HYD was car- 
Table 5. Peak purity results of OLM, AMD and HYD in forced degradation study.

\begin{tabular}{|c|c|c|c|c|c|c|c|c|c|}
\hline \multirow{2}{*}{$\begin{array}{c}\text { Stress } \\
\text { Condition }\end{array}$} & \multicolumn{3}{|c|}{ Purity Angle } & \multicolumn{3}{|c|}{ Purity Threshold } & \multicolumn{3}{|c|}{ Purity Flag } \\
\hline & OLM & AMD & HYD & OLM & AMD & HYD & OLM & AMD & HYD \\
\hline Thermal stress & 0.070 & 1.118 & 0.114 & 0.538 & 4.580 & 1.140 & No & No & No \\
\hline Aqueous Stress & 0.057 & 0.902 & 0.131 & 0.499 & 3.973 & 1.384 & No & No & No \\
\hline Acid Stress & 0.064 & 1.108 & 0.108 & 0.493 & 4.301 & 1.125 & No & No & No \\
\hline Base Stress & 0.065 & 1.306 & 0.122 & 0.536 & 5.057 & 1.212 & No & No & No \\
\hline Peroxide Stress & 0.060 & 1.727 & 0.241 & 0.533 & 5.776 & 1.202 & No & No & No \\
\hline
\end{tabular}

ried out by leaving the test solution in tightly capped volumetric flask at room temperature for $48 \mathrm{hr}$. The same sample solution was assayed for a 24 hours interval up to the study period against freshly prepared standard solution of OLM, AMD and HYD. The mobile phase stability was also carried out by assaying the freshly prepared standard solution for 24 hours interval up to 48 hours. The mobile phase preparation was kept constant during the study period. The percentage RSD of assay of OLM, AMD and HYD was calculated for the study pe- riod during mobile phase and solution stability experi- ments. The \%RSD of the assay of OLM, AMD and HYD during solution stability and mobile phase experiments were within $1 \%$ and it indicates that both standard and test preparation and mobile phase were stable for 2 days on bench top at room temperature.

\subsection{QC Results}

While using the above mentioned chromatographic conditions QC dept has a high quality results with out any abnormality. The batch results are with in specifications. In accuracy test the procedure shows good results at 50\%, $100 \%$ and $150 \%$ of test concentrations.

\section{Conclusion}

The established UPLC method proves to be simple, linear, precise, accurate and specific. The total runtime was 6.0 minutes within which three drugs and their degradation products were separated. The method was validated and shows satisfactory data for all the method validation parameters tested. The Developed method is stability indicating and can be used for simultaneous quantitative determination of the drugs OLM, AMD and HYD in presence of degradation products in stability by the industry. The adopted UPLC method also can be used separately for assay estimation of Olmesartan tablets, simultaneous estimation of Olmesartan and Hydrochlorothiazide tablets and simultaneous estimation of Amlodipine and Hydrochlorothiazide tablets.

\section{Acknowledgements}

The authors wish to thank the management of Centre for
Chemical Sciences, Institute of Sciences and Technology, JNTU Hyderabad for supporting this work.

\section{REFERENCES}

[1] International Conference on Harmonization, "Stability Testing of New Drug Substances and Products Q1 A (R2)," International Conference on Harmonization, IFPMA, Geneva, 2003.

[2] S. B. Wankhede, M. R. Tajane, K. R. Gupta and S. G. Wadodkar, "RP-HPLC Method for Simultaneous Estimation of Telmisartan and Hydrochlorothiazide in Tablet Dosage," Indian Journal of Pharmaceutical Sciences, Vol. 69, 2007, pp. 298-300. doi:10.4103/0250-474X.33164

[3] S. Singh and M. Bakshi, "Guidance on Conduct of Stress tests to Determine Inherent Stability of Drugs," Pharm Tech Online, Vol. 24, 2000, pp. 1-14.

[4] International Conference on Harmonization, "Photo Stability Testing of New Drug Substance and Products Q1B,” International Conference on Harmonization, IFPMA, Geneva, 1996.

[5] M. Bakshi and S. Singh, "Development of Validated Stability-Indicating Assay Methods-Critical Review," Journal of Pharmaceutical and Biomedical Analysis, Vol. 28, No. 6, 2002, pp. 1011-1040. doi:10.1016/S0731-7085(02)00047-X.

[6] S. Singh, B. Singh, R. Bahuguna, L. Wadhwa and R. Saxena, "Stress Degradation Studies on Ezetimibe and Development of a Validated Stability-Indicating HPLC Assay," Journal of Pharmaceutical and Biomedical Analysis, Vol. 41, No. 3, 2006, pp. 1037-1040. doi:10.1016/j.jpba.2006.01.030

[7] J. T. Carstensen and C. T. Rhodes, "Drug Stability: Principles and Practices,” 3rd Edition, Marcel Dekker, New York, 2000.

[8] N. Erk, "Analysis of Binary Mixtures of Losartan Potassium and Hydrochlorothiazide by Using High Performance Liquid Chromatography, Ratio Derivative Spectrophotometric and Compensation Technique," Journal of Pharmaceutical and Biomedical Analysis, Vol. 24, No. 4, 2001, pp. 603-611. doi:10.1016/S0731-7085(00)00434-9

[9] S. M. Al-Ghannam, "A Simple Spectrophotometric Method for the Determination of $\beta$-Blockers in Dosage," Journal of Pharmaceutical and Biomedical Analysis, Vol. 40, No. 1, 2006, pp. 151-156. doi:10.1016/j.jpba.2001.12.001 
[10] M. del R. Brunetto, Y. Contreras, S. Clavijo, D. Torres, Y. Delgado, F. Ovalles, C. Ayala, M. Gallignani, J. M. Estela, V. C. Martin, "Determination of Losartan, Telmisartan, and Valsartan by Direct Injection of Human Urine into a Column-Switching Liquid Chromatographic System with Fluorescence Detection," Journal of Pharmaceutical and Biomedical Analysis, Vol. 50, No. 2, 2009, pp. 194-199. doi:10.1016/j.jpba.2009.04.015

[11] T. T. Yan, H. Li, L. L. Deng, Y. J. Guo, W. S. Yu, J. P. Fawcett, D. Zhang, Y. M. Cui and J. K. Gu, "Liquid Chromatographic-Tandem Mass Spectrometric Method for the Simultaneous Quantitation of Telmisartan and Hydrochlorothiazide in Human Plasma," Journal of Pharmaceutical and Biomedical Analysis, Vol. 48, No. 4, 2008, pp. 1225-1229. doi:10.1016/j.jpba.2008.08.021

[12] H. W. Van den Bossche, "Simultaneous Determination of Hydrochlorothiazide and Several Angiotensin-II-Receptor Antagonists by Capillary Electrophoresis," Journal of Pharmaceutical and Biomedical An lysis, Vol. 31, No. 2, 2003, pp. 329-339. doi:10.1016/S0731-7085(02)00643-X

[13] L. V. Potale, M. C. Damle, A. S. Khodke and K. G. Bothara, "A Validated Stability Indicating HPTLC Method for Simultaneous Estimation of Ramipril and Telmisartan," International Journal of Pharmaceutical Sciences Review and Research, Vol. 2, 2010.
[14] V. G. Dongre, S. B. Shah, P. P. Karmuse, M. Phadke and V. K. Jadhav, "Simultaneous Determination of Meto- prolol Succinate and Amlodipine Besylate in Dosage form by HPLC," Journal of Pharmaceutical and Biomedical Analysis, Vol. 46, No. 3, 2008, pp. 583-586. doi:10.1016/i.jpba.2007.11.006

[15] P. Sudhakar, M. Nirmala, J. Moses Babu, K. Vyasa, Ganta Madhusudan Reddy, B. Vijaya Bhaskar, P. Pratap Reddy and K. Mukkanti, "Identification and Characterization of Potential Impurities of Amlodipine Maleate," Journal of Pharmaceutical and Biomedical Analysis, Vol. 40, No. 3, 2006, pp. 605-613. doi:10.1016/j.jpba.2005.10.029

[16] Y. S. Lakshmi Narasimham and V. D. Barhate, "Development and Validation of Stability Indicating UPLC Method for the Simultaneous Determination of Beta-Blockers and Diuretic Drugs in Pharmaceutical Dosage,” Journal of Chemical Metrology, Vol. 4, No. 1, 2010, pp. 1-20.

[17] K. R. Naidu, U. N. Kale and M. S. Shingare, "Stability Indicating RP-HPLC Method for Simultaneous Determination of Amlodipine and Benazepril Hydrochloride from Their Combination Drug Product," Pharmaceutical and Biomedical Analysis, Vol. 39, No. 1-2, 2005, pp. 147155. doi:10.1016/j.jpba.2005.04.001 